\title{
ESTUDO COMPARATIVO ENTRE SÍLICA OBTIDA POR LIXÍVIA ÁCIDA DA CASCA DE ARROZ E SÍLICA OBTIDA POR TRATAMENTO TÉRMICO DA CINZA DE CASCA DE ARROZ
}

\author{
Viviana Possamai Della e Dachamir Hotza* \\ Departamento de Engenharia Química e Engenharia de Alimentos, Universidade Federal de Santa Catarina, CP 476, \\ 88040-900 Florianópolis - SC, Brasil \\ Janaína Accordi Junkes e Antonio Pedro Novaes de Oliveira \\ Departamento de Engenharia Mecânica, Universidade Federal de Santa Catarina, CP 476, 88040-900 Florianópolis - SC, Brasil
}

Recebido em 24/5/05; aceito em 16/3/06; publicado na web em 13/7/06

\begin{abstract}
COMPARATIVE STUDY OF SILICA OBTAINED FROM ACID LEACHING OF RICE HUSK AND THE SILICA OBTAINED BY THERMAL TREATMENT OF RICE HUSK ASH. A comparison between silica by acid leaching of rice husk (RH) and silica obtained from thermal treatment of rice husk ash (RHA) is presented. The best leaching results were obtained using $10 \%$ hydrochloric acid followed by washing with water. The alternative method, calcination of RHA at $700^{\circ} \mathrm{C}$ for $6 \mathrm{~h}$ followed by grinding for 80 min, was more effective. Silica obtained from RH was about $97 \%$ amorphous, had a $17.37 \mu \mathrm{m}$ mean particle size, and a specific surface area of $296 \mathrm{~m}^{2} / \mathrm{g}$. On the other hand, for silica obtained from RHA the values were about $95 \%$ amorphous material $0.68 \mu \mathrm{m}$, and $81 \mathrm{~m}^{2} / \mathrm{g}$.
\end{abstract}

Keywords: silica; rice husk; acid leaching.

\section{INTRODUÇÃO}

Dióxido de silício $\left(\mathrm{SiO}_{2}\right)$, mais conhecido como sílica, é um composto químico que pode ser encontrado na natureza puro ou na forma de minerais. No estado puro é encontrado em rochas de quartzo, areia, arenitos e quartzitos. Como mineral apresenta-se em associações que dão origem a feldspatos, silicatos de magnésio e zircônia, dentre outros.

A sílica, pura ou como mineral, é um composto amplamente utilizado na indústria química inorgânica, com grande ênfase na indústria cerâmica, principalmente como matéria-prima para fabricação de vidros, refratários, tubos cerâmicos, isolantes térmicos e abrasivos. Na indústria da construção civil, como componente em cimentos, concretos e argamassas, a sílica tem fundamental importância, pois é responsável pela resistência mecânica, viscosidade e tempo de endurecimento. Devido a sua vasta aplicabilidade, o conhecimento de suas características é até hoje interesse de estudos para muitos pesquisadores ${ }^{1-6}$.

Motivados pela evolução tecnológica do beneficiamento do arroz, a casca de arroz (CA), resíduo gerado de elevado poder calorífico (aproximadamente $16720 \mathrm{~kJ} / \mathrm{kg}$, o qual corresponde a $50 \%$ da capacidade térmica de um carvão betuminoso de boa qualidade ${ }^{1}$ e a $33 \%$ da capacidade térmica do petróleo ${ }^{2}$ ), vem substituindo a lenha empregada na geração de calor nos secadores do grão. Esta utilização, ainda que pequena (somente $30 \%$ do montante), apresenta-se como uma alternativa adequada para aproveitamento deste resíduo. Porém, deste processo resulta um novo resíduo, a cinza de casca de arroz (CCA), que contém além de matéria orgânica remanescente, pó de sílica, com partículas de forma acicular, que quando inaladas causam doença ao sistema respiratório, a silicose, e em contato com a pele, irritação. A casca de arroz, assim como a cinza excedente, são depositadas a céu aberto em beiras de estradas e margens de rios.

As tentativas de uso destes dois resíduos enfrentam constantemente dificuldades devido a propriedades inerentes, tais como dureza, fibrosidade, natureza abrasiva, baixo valor nutritivo, difícil

*e-mail: hotza@enq.ufsc.br degradabilidade, grande volume e alto teor residual. Porém, pesquisas desenvolvidas com base nestes resíduos comprovam a viabilidade de sua utilização em várias áreas ${ }^{3-10}$.

Pesquisas sobre o potencial destes como fonte de sílica, têm sido relatadas há vários anos, e estão fundamentadas no fato de que extraída a matéria orgânica e os compostos alcalino e alcalinoterrosos indesejáveis, cerca de $95 \%$ de sílica no estado amorfo pode ser obtida ${ }^{3}$. O interesse na extração da sílica a partir destes resíduos provém da potencialidade de ser obtida com elevada área de superfície específica e pureza ${ }^{6}$.

A sílica existe na CA e na CCA e, além do processo de simples combustão, pode ser obtida através do tratamento físico-químico com soluções de diferentes ácidos em várias concentrações, seguido de lavagem com água deionizada e queima da parte orgânica em determinados $\operatorname{ciclos}^{11-13}$.

Com base nos argumentos mencionados acima, este trabalho teve por objetivo apresentar uma alternativa de utilização para a casca de arroz e sua cinza empregando procedimentos de lixívia ácida e tratamento térmico, respectivamente. Os produtos obtidos a partir destes processamentos foram caracterizados e analisados visando sua utilização na obtenção de pigmentos cerâmicos e como substitutos da sílica ativa ou microssílica na formulação de concretos de alto desempenho, respectivamente.

\section{PARTE EXPERIMENTAL}

\section{Matéria-prima}

A casca de arroz bem como a cinza utlizadas neste trabalho foram cedidas pela Indústria e Comércio de Arroz Fumacense (Morro da Fumaça, SC).

\section{Métodos}

A obtenção da sílica a partir da CA foi dividida em duas etapas. Primeiramente, a CA passou por um processo de lavagem com água deionizada para remoção de sujeiras superficiais (poeira e terra) e 
outros contaminantes possivelmente presentes, com posterior secagem em estufa à $110^{\circ} \mathrm{C}$ por $24 \mathrm{~h}$. Para a lixívia, utilizaram-se 30 g de CA lavada para cada $500 \mathrm{~mL}$ de solução $(\mathrm{HCl}$ - Quimex $10 \%$ em volume, $\mathrm{H}_{2} \mathrm{SO}_{4}$ - Quimex $10 \%$ em volume, e mistura de $10 \%$ de $\mathrm{HCl}$ com $10 \%$ de $\mathrm{H}_{2} \mathrm{SO}_{4}$ em volume). Um béquer contendo a solução ácida e a CA foi colocado sobre uma placa aquecedora até fervura, permanecendo $2 \mathrm{~h}$ em ebulição. Retirada da solução ácida, a casca lixiviada foi lavada com água deionizada até se obter pH entre 5 e 6 e, em seguida, submetida à secagem. A lixívia teve por objetivo a retirada dos íons alcalinos e alcalinos terrosos presentes na casca. A segunda etapa do processo consistiu em submeter a casca lixiviada a calcinações com patamares de $3 \mathrm{~h}$ a 600 e $700{ }^{\circ} \mathrm{C}$ com taxa de aquecimento de $5{ }^{\circ} \mathrm{C} / \mathrm{min}$, em forno Schaly (modelo Lab 44-1280) para eliminação da matéria orgânica e compostos voláteis. Os melhores resultados foram obtidos com as amostras lixiviadas com solução de $\mathrm{HCl} 10 \%$ e calcinadas à $600{ }^{\circ} \mathrm{C}$. Esta etapa do trabalho foi desenvolvida por Junkes et al. ${ }^{14}$ no Centro de Tecnologia em Materiais (CTCmat - Criciúma).

A obtenção da sílica a partir da CCA consistiu em submeter amostras de cinza, sem nenhum tipo de tratamento prévio, a ciclos térmicos em forno Shaly (modelo Lab 18-1300CR) nas temperaturas de 400, 500, 600 e $700{ }^{\circ} \mathrm{C}$ por períodos de 1,3 e $6 \mathrm{~h}$, com taxa de aquecimento de $10{ }^{\circ} \mathrm{C} / \mathrm{min}$. O produto obtido foi submetido a moagem a úmido durante 10,40 e $80 \mathrm{~min}$. Os melhores resultados foram obtidos com a amostra calcinada à $700^{\circ} \mathrm{C}$ com patamar de $6 \mathrm{~h}$, seguida de moagem durante $80 \mathrm{~min}$. Esta etapa do trabalho foi desenvolvida por Della ${ }^{8,15}$ na Universidade Federal de Santa Catarina.

A caracterização da CA, da CCA e da sílica resultante foi obtida através do emprego de técnicas de fluorescência de raios-X em aparelho Phillips (modelo PW 24000), difração de raios-X em difratômetro Phillips (modelo Xpert), microscopia eletrônica de varredura em microscópio Phillips (modelo XL 30), distribuição do tamanho de partículas segundo a técnica de difratometria a laser em equipamento Cilas (modelo 1064L) e área de superfície específica pelo método B.E.T. (Brunauer, Emmett e Teller), em equipamento Quantachrome Autosorb. Para realização da medida colorimétrica foi utilizado espectrofotômetro HunterLab (modelo ColorQuest) de geometria $45^{\circ} 0^{\circ}$ com fonte de iluminação D65 e ângulo de observação padrão $10^{\circ}$. Como escala de leitura colorimétrica adotou-se o sistema de coordenadas cromáticas L* $\mathrm{a}^{*}$ b* da CIE ("Commission Internationale de I'Eclairage" - Comissão Internacional de Iluminação).

\section{RESULTADOS E DISCUSSÃO}

A Figura 1 apresenta as características morfológicas macroscópicas de ambos os resíduos. A casca de arroz, Figura 1a, apresenta partículas grandes de coloração amarelo palha. Já a cinza da casca de arroz, Figura 1b, por ser obtida após queima da casca nas usinas de beneficiamento do grão, apresenta coloração preta predominante, com algumas partículas de cor cinza claro resultantes da maior oxidação do carbono durante a queima.

Os elementos metálicos, alcalinos e alcalino-terrosos presentes em ambos resíduos, relacionados na Tabela 1, são os responsáveis pela formação de silicatos durante a calcinação, comprometendo a pureza da sílica a ser obtida. $\mathrm{O}$ ataque químico solubiliza estes elementos, que durante a lavagem seqüencial são removidos, propiciando a obtenção de sílica livre de impurezas após calcinação a temperaturas mais baixas. Além da remoção dos íons solubilizados, a lavagem também tem por objetivo a retirada do excesso de ácido utilizado na lixívia.

A composição química da CA e em conseqüência da sua cinza (quando esta não for submetida a ataque químico), varia em função
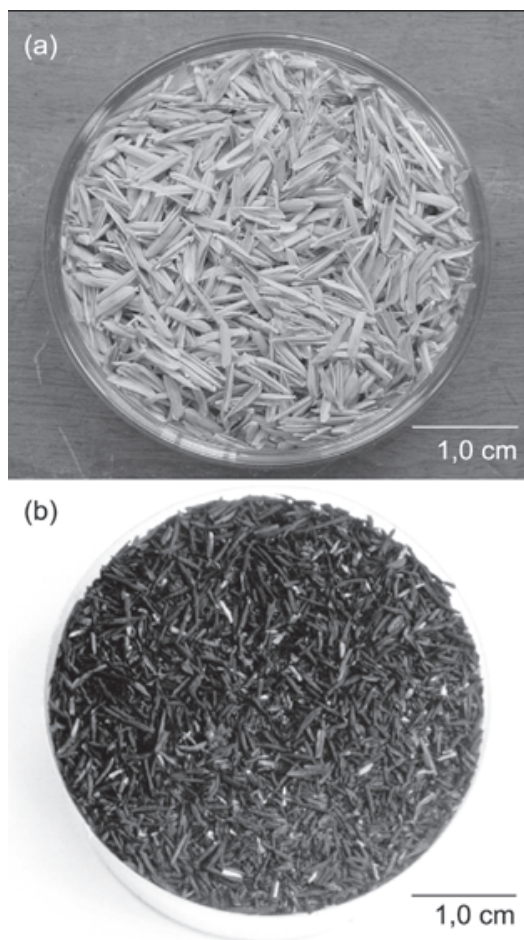

Figura 1. Resíduos sem tratamento: (a) casca de arroz; (b) cinza de casca de arroz

do solo em que o arroz é plantado, dos tipos e teores de fertilizantes utilizados, das condições climáticas, bem como do tipo de arroz propriamente dito. $\mathrm{O} \mathrm{K}_{2} \mathrm{O}$ e o $\mathrm{P}_{2} \mathrm{O}_{5}$ presentes são oriundos do tipo de fertilizante usado na plantação do arroz, e o restante das impurezas proveniente do solo ${ }^{3}$.

A composição inicial dos dois resíduos não variou substancialmente, devido ao fato de que a indústria que os gera também é responsável pelo plantio do cereal, realizado sob condições relativamente constantes.

Tabela 1. Composição química por fluorescência de raios-X da casca de arroz CA e da cinza de casca de arroz CAA in natura

\begin{tabular}{lcc}
\hline Óxidos & Composição* da CA & Composição* da CCA \\
\hline $\mathrm{SiO}_{2}$ & 13,55 & 72,10 \\
$\mathrm{Al}_{2} \mathrm{O}_{3}$ & 0,04 & 0,30 \\
$\mathrm{Fe}_{2} \mathrm{O}_{3}$ & 0,01 & 0,15 \\
$\mathrm{CaO}$ & 0,10 & 0,43 \\
$\mathrm{MgO}$ & 0,05 & 0,70 \\
$\mathrm{~K}_{2} \mathrm{O}$ & 0,03 & 0,72 \\
$\mathrm{Na}_{2} \mathrm{O}$ & 0,02 & 0,50 \\
$\mathrm{MnO} \mathrm{O}$ & 0,15 \\
$\mathrm{TiO}_{2}$ & 0,02 & 0,05 \\
$\mathrm{P}_{2} \mathrm{O}_{5}$ & $<0,01$ & 0,60 \\
Perda ao fogo & 0,05 & 24,30 \\
\hline
\end{tabular}

* percentual em massa

A Figura 2 apresenta as micrografias dos resíduos analisados, nas quais se pode avaliar detalhadamente a morfologia dos mesmos. Analisando a morfologia apresentada nas Figuras $1 b$ e 2b, podese perceber claramente que devido ao fato da CCA já ter sido submetida a uma calcinação prévia, suas partículas possuem formato alongado e contorcido, com aparência de espigas de milho ${ }^{16}$, provo- 
cado pelo processo de queima. Porém a casca, Figuras 1a e 2a, mantém o formato natural, salvo pela aparência fraturada ocasionada pela retirada do grão.

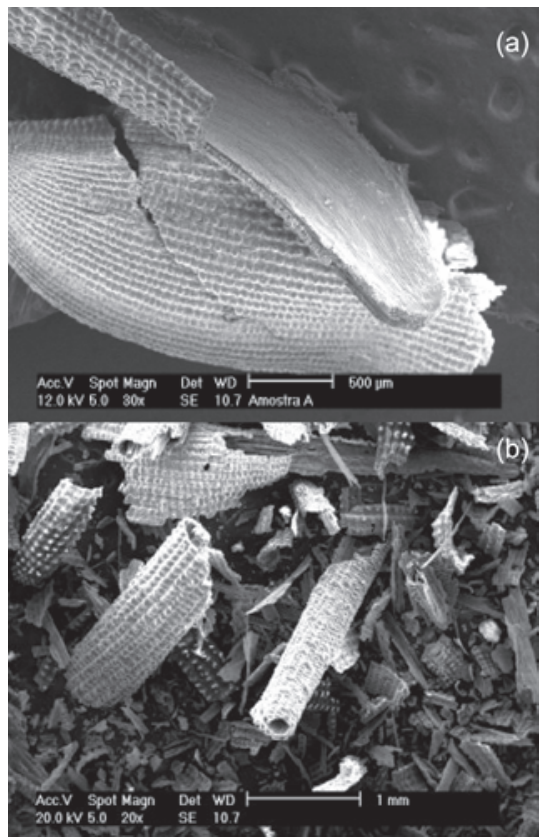

Figura 2. Morfologia típica: (a) casca de arroz; (b) cinza de casca de arroz

Em ambas micrografias é claramente visível a diferença entre a rugosidade da epiderme externa das partículas, região que concentra o maior percentual de sílica, e o aspecto liso da epiderme interna, região onde se encontram em maior concentração a celulose e a lignina, principais compostos orgânicos da casca.

A sílica presente na casca, e por conseqüência na cinza, está concentrada principalmente dentro da epiderme externa em direção ao meio da estrutura da casca. No entanto, uma pequena mas significante quantidade de sílica reside na epiderme interna, adjacente ao grão de arroz ${ }^{17}$.

A Figura 3 mostra o aspecto da CA após a lixívia ácida e o aspecto da CCA após o tratamento térmico. Quando se compara a imagem da CA da Figura 3a com a Figura 1a, pode-se notar que a coloração da mesma mudou, tornando-se mais escura em relação a esta. O formato das partículas também sofreu variação, apresentando-se mais contorcidas devido ao tempo de fervura ácida a que foram submetidas.

Em comparação com a amostra de CCA antes do tratamento térmico, Figura 1b, a sílica resultante apresentou coloração predominante entre cinza claro e escuro, Figura 3b, com grande parte das partículas de cor branca, evidenciando a quase total eliminação do carbono presente. Nota-se, porém, que ainda permanecem partículas de cor preta, confirmando a presença de carbono.

Houston $^{3}$ classificou a cor da CCA em função do teor de carbono presente. Assim, as cinzas de coloração preta possuem alto conteúdo de carbono, as de coloração cinza claro baixo conteúdo de carbono, e as de coloração branca ou levemente rosadas são isentas de carbono.

$\mathrm{O}$ ataque ácido proposto para o tratamento da CA mostrou-se realmente efetivo na redução das impurezas metálicas, Tabela 2 , principalmente na redução do percentual de potássio e sódio, elementos que interferem negativamente sobre a área de superfície específica da sílica.

Analisando a composição química da sílica obtida com o trata-
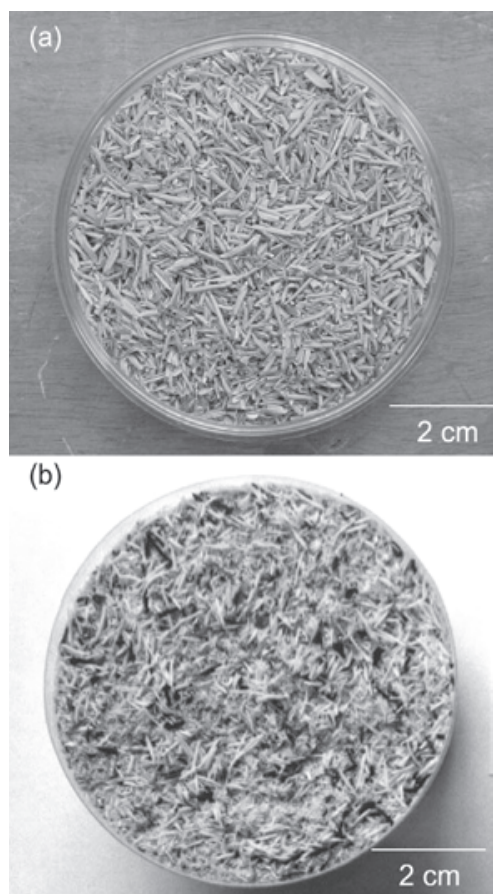

Figura 3. Aspecto das amostras após tratamento: (a) casca de arroz lixiviada; (b) cinza de casca de arroz tratada termicamente

mento térmico aplicado na CCA, verificou-se que este se mostrou efetivo somente na redução da perda ao fogo (matéria orgânica) e que o percentual relativo às impurezas metálicas aumentou em sua maioria.

O conteúdo de carbono presente na sílica (representado pela cor escura) utilizada em concretos é um bom indicador da sua qualidade, pois um baixo conteúdo deste reflete em maior resistência ao concreto formulado ${ }^{18}$.

Tabela 2. Composição química por fluorescência de raios-X da sílica obtida após tratamento da casca de arroz e da cinza

\begin{tabular}{lcc}
\hline Óxidos & $\begin{array}{c}\text { Composição* da } \\
\text { sílica de CA }\end{array}$ & $\begin{array}{c}\text { Composição* da } \\
\text { sílica de CCA }\end{array}$ \\
\hline $\mathrm{SiO}_{2}$ & 96,91 & 94,95 \\
$\mathrm{Al}_{2} \mathrm{O}_{3}$ & 0,43 & 0,39 \\
$\mathrm{Fe}_{2} \mathrm{O}_{3}$ & 0,02 & 0,26 \\
$\mathrm{CaO}$ & 0,07 & 0,54 \\
$\mathrm{MgO}$ & 0,05 & 0,90 \\
$\mathrm{~K}_{2} \mathrm{O}$ & $<0,01$ & 0,94 \\
$\mathrm{Na}_{2} \mathrm{O}$ & 0,07 & 0,25 \\
$\mathrm{MnO} \mathrm{TiO}_{2}$ & 0,16 \\
$\mathrm{P}_{2} \mathrm{O}_{5}$ & 0,01 & 0,02 \\
$\mathrm{Perda}$ ao fogo & 0,01 & 0,74 \\
& 0,02 & 0,85
\end{tabular}

* percentual em massa

Apesar da diferença entre o percentual de $\mathrm{SiO}_{2}$ obtido pelos dois processos ter sido pequeno $(1,96 \%)$, percebe-se que a sílica obtida a partir da CCA apresenta alto percentual de impurezas (entre 0,02 e $0,94 \%)$, especialmente potássio $(0,94 \%)$, fazendo com que esta, mesmo apresentado menor percentual de perda ao fogo, tenha coloração acinzentada devido ao aprisionamento do carbono dentro da fase líquida formada na superfície das partículas de cinza pela dissociação e posterior fusão dos óxidos fundentes ${ }^{19}$. Como no processo de lixívia 
as impurezas metálicas são dissociadas e posteriormente removidas na lavagem subseqüente, o carbono é liberado normalmente durante a calcinação, resultando em uma sílica de maior pureza.

As coordenadas colorimétricas $\mathrm{L}^{*} \mathrm{a}^{*} \mathrm{~b}^{*}$ foram obtidas com base no espaço de cor CIELAB, onde L* é uma indicação de claro e escuro, $a^{*}$ é uma indicação de tonalidade na direção do verde $\left(-a^{*}\right)$ para o vermelho $\left(+a^{*}\right)$ e b* é uma indicação de tonalidade na direção do azul (-b*) para o amarelo $\left(+b^{*}\right)$.

Foram obtidas como coordenadas colorimétricas para a sílica a partir da CA: $\mathrm{L}^{*}=83,26, \mathrm{a}^{*}=0,04 \mathrm{e}^{*}=0,75$. Para a sílica a partir da CCA foram determinadas as coordenadas $\mathrm{L}^{*}=57,23$, $\mathrm{a}^{*}$ $=0,14 \mathrm{e} \mathrm{b}^{*}=1,22$. Verifica-se que apesar das coordenadas de ambos materiais se localizarem dentro da região compreendida pelo vermelho e amarelo, estes valores são muito baixos, fazendo com que a cor predominante para a sílica da CA seja o branco, devido ao alto valor de $\mathrm{L}^{*}$ que está localizado acima de 50, caracterizando alta luminosidade, e, para a sílica da CCA a tonalidade resultante é o cinza claro devido ao valor da coordenada $L^{*}$ ser também superior a 50 , situando-se na região de alta luminosidade.

A sílica obtida por combustão da CA, tratada ou não com solução ácida, apresenta-se na forma amorfa ${ }^{20}$, pois esta não modifica a estrutura da sílica, estando consistente com o presente estudo, Figura 4a.

O reaquecimento da CCA para remoção do carbono a temperaturas acima de $800{ }^{\circ} \mathrm{C}$, faz com que o potássio e o sódio contidos acelerem tanto a fusão das partículas quanto a cristalização da cristobalita a partir da sílica amorfa, por baixar o ponto de fusão do material ${ }^{21,22}$. Entretanto, a tendência destes elementos em acelerar a cristalização da sílica não foi evidenciada neste estudo devido às temperaturas aplicadas terem sido inferiores à especificada, Figura 4b.

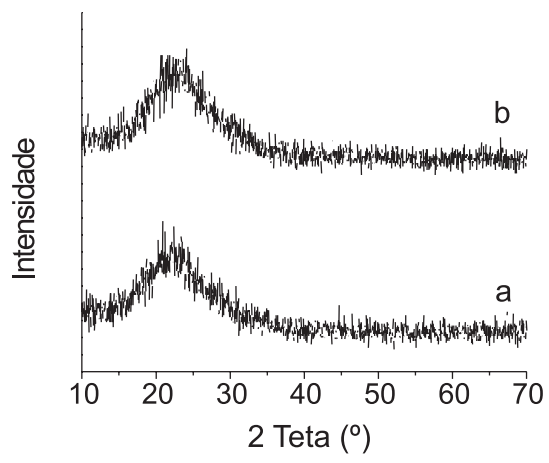

Figura 4. Difratogramas de raios-X da sílica obtida: (a) casca de arroz, (b) cinza de casca de arroz

A CA lixiviada livre de impurezas metálicas gerou sílica de menor granulometria, diâmetro médio de $17,37 \mu \mathrm{m}$, sendo $100 \%$ destas inferiores a $56 \mu \mathrm{m}$. Embora este valor ainda seja considerado elevado, sua área de superfície específica determinada foi de $296 \mathrm{~m}^{2} / \mathrm{g}$. A redução da distribuição granulométrica pode ser feita por micronização, como uma etapa subseqüente do processo. Por apresentar alto conteúdo de $\mathrm{SiO}_{2}$ e área de superfície específica, esta sílica pode ser utilizada após micronização como matéria-prima na obtenção de materiais nobres, como pigmentos cerâmicos.

Analisando a imagem da Figura 3b, observa-se que o tamanho das partículas de cinza continua grande, o que dificulta seu uso em concretos de alto desempenho, uma vez que a microssílica normalmente utilizada possui diâmetro médio entre 0,03 e $0,15 \mu \mathrm{m}$, Tabela 3. Deste modo, a cinza obtida depois do tratamento térmico necessita ser moída para atingir a granulometria adequada. Submeti- da ao processo de moagem durante 80 min, a sílica atingiu diâmetro médio de $0,68 \mu \mathrm{m}$ com $100 \%$ das partículas abaixo de $6 \mu \mathrm{m}$, Figura 5b. Apesar do diâmetro médio das partículas obtidas ter sido maior, isto não reduz a qualidade do produto, já que as sílicas comercializadas possuem de 0,2 a $10 \%$ de resíduo retido na malha 325 mesh, o que corresponde a $44 \mu \mathrm{m}$.

Tabela 3. Parâmetros de comparação entre a sílica obtida a partir da cinza de casca de arroz e as microssílicas comerciais

\begin{tabular}{lcc}
\hline Parâmetros & Microssílicas Comerciais* Sílica de CCA \\
\hline Teor de $\mathrm{SiO}_{2}$ (mín.) & 78 a $98 \%$ & $94,95 \%$ \\
$\begin{array}{l}\text { Perda ao fogo (máx.) } \\
\text { Retido em malha 325 }\end{array}$ & 0,6 a $6 \%$ & $0,85 \%$ \\
mesh (máx.) & 0,2 a $10 \%$ & 0 \\
$\begin{array}{l}\text { Tamanho médio } \\
\text { de partícula }\end{array}$ & 0,03 a $0,15 \mu \mathrm{m}$ & $0,68 \mu \mathrm{m}$ \\
$\begin{array}{l}\text { Área de superfície } \\
\text { específica }\end{array}$ & 15 a $28 \mathrm{~m}^{2} / \mathrm{g}$ & $81 \mathrm{~m}^{2} / \mathrm{g}$ \\
Estrutura por raios-X & amorfa & amorfa \\
\hline
\end{tabular}

* Refs. 23 e 24
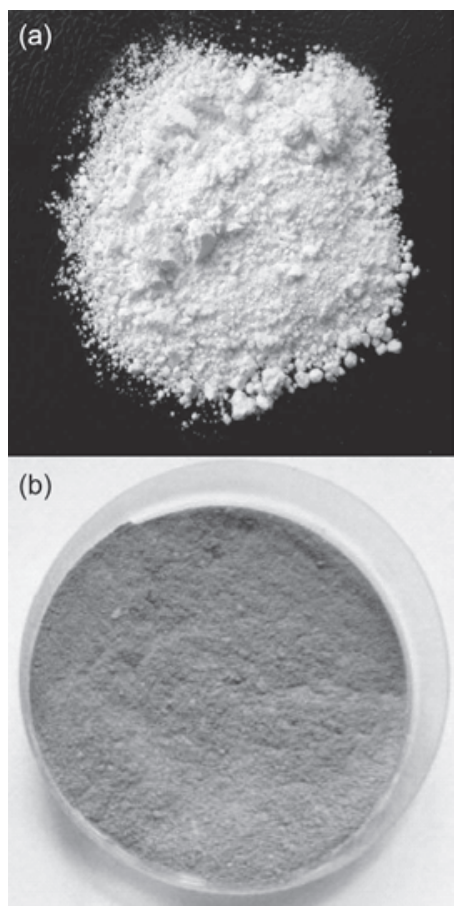

Figura 5. Produtos (sílica) obtidos: (a) casca de arroz lixiviada e calcinada; (b) cinza de casca de arroz tratada termicamente e moída

Com esta faixa granulométrica a sílica obtida a partir da CCA atingiu área de superfície específica de $81 \mathrm{~m}^{2} / \mathrm{g}$, valor relativamente alto se levado em consideração o percentual de impurezas contido e a área superficial das microssílicas comercializadas.

\section{CONCLUSÕES}

A tendência do aproveitamento integral de resíduos é uma necessidade cada vez maior na indústria moderna, especialmente quando esta busca a certificação ISO 14000 .

Devido ao seu elevado percentual de sílica, os resíduos CA e CCA são valorizados sob o ponto de vista econômico, considerando aspectos como área de superfície específica, distribuição de ta- 
manho e pureza das partículas. Conseqüentemente, não utilizá-los apropriadamente é um grande desperdício de matéria-prima nobre. Desta forma, através de procedimentos simples, é possível transformar resíduos normalmente descartados em produtos úteis e, assim, evitar danos ao meio ambiente.

Com base nos resultados apresentados neste estudo, pode-se concluir que é possível obter sílica a partir da casca de arroz, bem como da cinza de casca de arroz, com características de pureza, área de superfície específica e cor adequadas para uso na composição de materiais, como concretos de alto desempenho e pigmentos cerâmicos. Para se comprovar a possibilidade de uso da sílica de CA ou CCA deve-se efetuar ensaios de processabilidade e propriedades pós-cura, no caso de concretos, e de capacidade de encapsulamento e desempenho em relação à cor, no caso de pigmentos.

\section{AGRADECIMENTOS}

Ao Centro de Tecnologia em Materiais (CTCmat), em Criciúma, $\mathrm{SC}$, pela parceria na realização dos ensaios, e ao CNPq pelo auxílio financeiro na forma de bolsa de doutorado.

\section{REFERÊNCIAS}

1. Gutierrez, R. M.; Delvasto, S.; Materiali Processi 1995, 25, 1.

2. Kapur, P. C.; Powder Technol. 1985, 44, 63

3. Houston, D. F.; Rice: Chemistry and Technology. American Association of Cereal Chemists: St. Paul, MN, 1972.
4. Govindarao, V. M. H.; J. Sci. Ind. Res. 1980, 39, 495

5. Fonseca, M. R. G.; Tese de Doutorado, Universidade Federal do Rio Grande do Sul, Brasil, 1999.

6. Souza, M. F.; Yamamoto, J.; Cerâmica 1999, 45, 34

7. Khalid, N.; Ahmad, S.; Toheed, A.; Ahmed, J.; Appl. Radiat. Isot. 2002, 52,31 .

8. Della, V. D.; Dissertação de Mestrado, Universidade Federal de Santa Catarina, Brasil, 2001.

9. Della, V. D.; Kühn, I.; Hotza, D.; Quim. Nova 2001, 24, 778.

10. http://www.ufsm.br/cenergia/arte_final.pdf, acessada em Maio 2005.

11. Real, C.; Alcalá, M. D.; Criado, J. M.; J. Am. Ceram. Soc. 1996, 79, 2012

12. Yalçin, N.; Sevinç, V.; Ceram. Int. 2001, 27, 219.

13. Souza, M. F.; Magalhães, W. L. E.; Persegil, M. C.; Mater. Res. 2002, 5, 467.

14. Junkes, J. A.; Della, V. P.; Acchar, W.; Oliveira; A. P. N.; Hotza, D.; Congresso Brasileiro de Ciência e Tecnologia em Resíduos e Desenvolvimento Sustentável, Anais do ICTR, Florianópolis, Brasil, 2004.

15. Della, V. P.; Kühn, I.; Hotza, D.; Br PI 0102680-1, 2001.

16. Amick, J. A.; J. Electrochem. Soc. 1982,129, 864.

17. James, J.; Rao, M. S.; Thermochim. Acta 1985, 97, 329

18. Larrard, F.; Gorse, J. F.; Puch, C.; Mater. Struct. 1992, 25, 265.

19. Krishnarao, R. V.; Subrahmanyam, J.; Kumar, T. J.; J. Ceram. Soc. 2000, 21, 99.

20. Chakraverty, A.; Mishra, P.; Banerjee, H. D.; J. Mater. Sci. 1988, 23, 21

21. Nakata, Y.; Suzuki, M.; Okutani, T.; Kikuchi, M.; Akiyama, T.; J. Ceram. Soc. Jpn. 1989, 97, 830

22. Chandrasekhar, S.; Satyanarayana, K. G.; Pramada, P. N.; Gupta, T. N.; J. Mater. Sci. 2003, 38, 3159.

23. Microsilica Tecnologia Indústria e Comércio Ltda; Catálogo de Descrição de Produtos, São Paulo, [S. D.].

24. http://www.norchem.com/tech-specs.html, acessada em Maio 2005. 